\title{
Pulmonary vascular anomalies: a review of clinical and radiological findings of cases presenting with different complaints in childhood
}

\author{
Hikmet Tekin Nacaroğlu${ }^{1}$, Canan Şule Ünsal-Karkıner ${ }^{1}$, Semiha Bahçeci-Erdem ${ }^{1}$, \\ Rahmi Özdemir ${ }^{2}$, Aytaç Karkıner ${ }^{3}$, Hüdaver Alper ${ }^{4}$, Demet Can ${ }^{1}$ \\ Divisions of ${ }^{1}$ Pediatric Allergy, ${ }^{2}$ Pediatric Cardiology, and ${ }^{3}$ Pediatric Surgery, Dr Behçet Uz Children's Hospital and \\ ${ }^{4}$ Department of Radiology, Ege University Faculty of Medicine, İzmir, Turkey.E-mail: tekin212@gmail.com \\ Received: 21 July 2015, Revised: 24 February 2016, Accepted: 7 March 2016
}

\begin{abstract}
SUMMARY: Nacaroğlu HT, Ünsal-Karkıner CŞ, Bahçeci-Erdem S, Özdemir R, Karkıner A, Alper H, Can D. Pulmonary vascular anomalies: A review of clinical and radiological findings of cases presenting with different complaints in childhood. Turk J Pediatr 2016; 58: 337-342.

Congenital pulmonary vascular abnormalities arise from several etiologies. These anomalies are difficult to categorize and sorted into distinct classifications. Major pulmonary vascular abnormalities can be ranked as interruption of the main pulmonary artery or its absence, emergence of the left pulmonary artery in the right pulmonary artery, pulmonary venous drainage abnormalities, and pulmonary arteriovenous malformations (PAVMs). Some of the cases are asymptomatic and diagnosed by coincidence, whereas a few of them are diagnosed by typical findings in the newborn and infancy period, symptoms, and radiological appearances. Early diagnosis is important, since death may occur as a result of pulmonary and cardiac pathologies developed in patients with pulmonary vascular anomalies. In this case presentation, the clinical and radiological findings of patients that presented with different complaints and were diagnosed with pulmonary vascular anomalies were introduced.
\end{abstract}

Key words: childhood, pulmonary arteriovenous malformation, pulmonary vascular malformations.

Congenital pulmonary vascular malformations are classified into very different forms. This difference arises from the relationship between the lung's one or more components' with the other. Major pulmonary vascular abnormalities can be classified as interruption of the main pulmonary artery or its absence, the emergence of the left pulmonary artery in the right pulmonary artery, pulmonary venous drainage abnormalities, and pulmonary arteriovenous malformations ${ }^{1-4}$. Pulmonary arteriovenous malformations (PAVMs) are caused by the incomplete formation of vascular septa dividing the primitive connections between the vein-artery plexus or its disintegration. More than $70 \%$ of pulmonary arteriovenous malformations are congenital ${ }^{4-6}$. Forty-seven to eighty percent of congenital PAVMs present themselves with Rendu-Osler-Weber syndrome (ROWS) or they are found with autosomal dominant pathology, also known as hereditary hemorrhagic telangiectasia $(\mathrm{HHT})^{7}$. Patients with PAVMs can be asymptomatic or admit to the emergency services with shortness of breath, tachycardia, exercise intolerance, epistaxis, cough, and hemoptysis. In addition, the classical triad consisting of cyanosis, polycythemia, and clubbing of the fingers can be observed in patients whose right to left shunt is $30 \%$ or more. The incidence of the classical triad is approximately $20 \%{ }^{6-8}$. In this case series, the clinical and radiological findings of five children who were admitted to our hospital with different complaints and diagnosed with pulmonary vascular malformation were presented.

\section{Case Reports}

The first case is a 5-year-old male patient with recurrent wheezing and whose etiology was 
Table I. Patients' Characteristics

\begin{tabular}{|c|c|c|c|c|}
\hline Case & Age & Gender & Clinical findings & Radiological findings \\
\hline 1 & 5 years & Male & $\begin{array}{l}\text { Recurrent wheezing, } \\
\mathrm{SpO}_{2}: 98 \%\end{array}$ & $\begin{array}{l}\text { AVM in the medial sub-segment localization of } \\
\text { the right superior lower lobe segment, diffusing } \\
\text { partially to the lower medial lobe and posterior basal } \\
\text { segments. }\end{array}$ \\
\hline 2 & 5 years & Male & $\begin{array}{l}\text { Finger clubbing, } \\
\text { cyanosis, } \\
\mathrm{SpO}_{2}: 82 \%\end{array}$ & $\begin{array}{l}\text { AVM, which drains to the inferior pulmonary vein by } \\
\text { forming a large abnormal vascular tissue in the right } \\
\text { upper and lower lobes of the lung. }\end{array}$ \\
\hline 3 & 6 months & Female & $\begin{array}{l}\text { Persistent cough, } \\
\text { wheezing, } \\
\mathrm{SpO}_{2}: 99 \%\end{array}$ & $\begin{array}{l}\text { Fissures in the right lung had not completely } \\
\text { developed. There was a partial venous anomaly in } \\
\text { the inferior pulmonary vein and the right lower lobe } \\
\text { of the lung, perfused from the celiac artery. }\end{array}$ \\
\hline 4 & 2 years & Female & $\begin{array}{l}\text { Polycythemia, cyanosis } \\
\text { and clubbing of the } \\
\text { fingers, } \\
\mathrm{SpO}_{2}: 75 \%\end{array}$ & $\begin{array}{l}\text { AVM in the right lower lobe, which were connected } \\
\text { to the right pulmonary veins and enlarged right } \\
\text { pulmonary artery. }\end{array}$ \\
\hline 5 & 13 years & Female & $\begin{array}{l}\text { Cough, cyanosis } \\
\text { and clubbing of the } \\
\text { fingers, } \\
\mathrm{SpO}_{2}: 76 \%\end{array}$ & $\begin{array}{l}\text { AVM characterized by a glomerulus with a diameter } \\
\text { of } 38 \mathrm{~mm} \text {, and was nourished by a large pulmonary } \\
\text { artery branch in the right medial lobe segment. }\end{array}$ \\
\hline
\end{tabular}

AVM: arteriovenous malformation

unclear. He remained symptomatic, despite inhaled steroids. The thorax CT revealed arteriovenous malformation (AVM) in the medial sub-segment localization of the right superior lower lobe segment, diffusing partially to the lower medial lobe and posterior basal segments. A vascular structure wider than $2 \mathrm{~cm}$ was observed, extending to this area in the intermediary pulmonary artery trunk and more than one drainage vein drained into the inferior pulmonary vein (Fig. 1). Transcatheter embolization was planned and sent to a specialized center.

The second case was a 5-year-old male. He

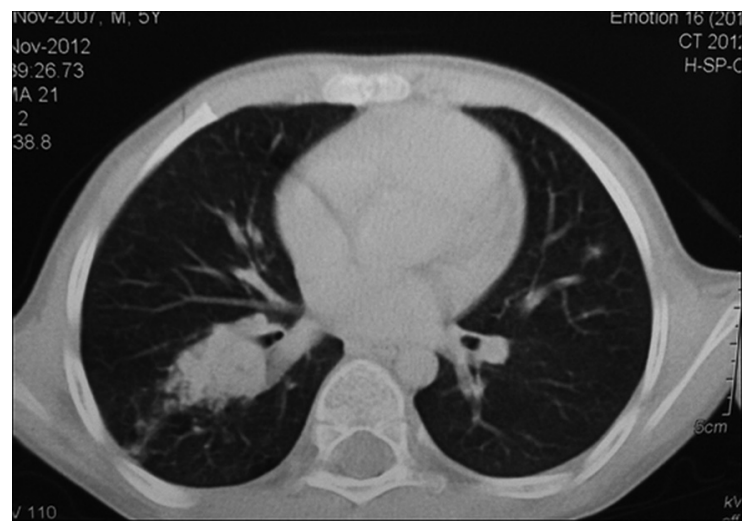

Fig. 1. The view from the thoracic CT of the first case, which is consistent with arteriovenous malformation in the medial segment localization of right lower lobe. was admitted to our hospital with a color change in the nails. In his physical examination at admission: body weight $17.3 \mathrm{~kg}$ (10-25p), height $112 \mathrm{~cm}$ (50-75p), body temperature $37^{\circ} \mathrm{C}$, respiratory rate 22 breaths $/ \mathrm{min}$, blood pressure $90 / 60 \mathrm{mmHg}, \mathrm{SpO}_{2} 82 \%$. His respiratory system and cardiovascular system examinations were normal. There was no pathological examination finding other than clubbing deformity of the fingers of the hand and cyanosis of the nails. In the laboratory tests: hemoglobin $14 \mathrm{~g} / \mathrm{dl}$, hematocrit $41.9 \%$, WBC $9,000 / \mathrm{mm}^{3}$ (52\% polymorphonuclear, $48 \%$ lymphocytes), platelets $376,000 / \mathrm{mm}^{3}$, erythrocyte sedimentation rate (ESR) $23 \mathrm{~mm} /$ hour; biochemical tests were normal. The echocardiographic examination was normal and the AVM, which drains to the inferior pulmonary vein by forming a large abnormal vascular tissue in the right upper and lower lobes of the lung, was determined in his thorax CT. However, it was thought that the patient could have Osler-Weber-Rendu Syndrome, as there were numerous small AVMs in different localizations (Fig. 2).

The third patient was a 6-month-old female infant who had a persistent cough and wheezing complaints for the past one month. No symptomatic amelioration was observed despite the treatment. In the physical examination 


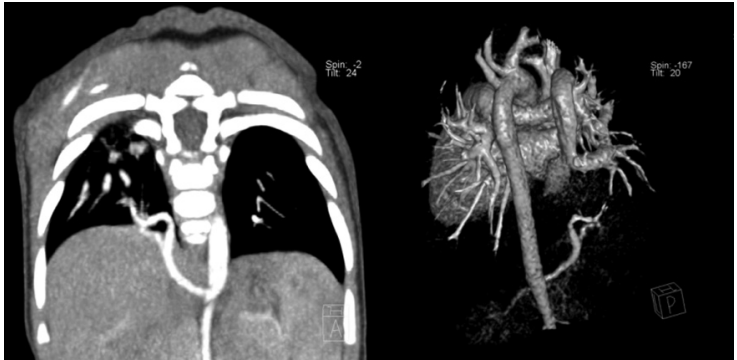

Fig. 2. The view from the thoracic CT of the second case, which is consistent with arteriovenous malformation causing conglomerate serpiginous large abnormal vascular tissue in the right lung lower lobe and draining into inferior pulmonary vein.

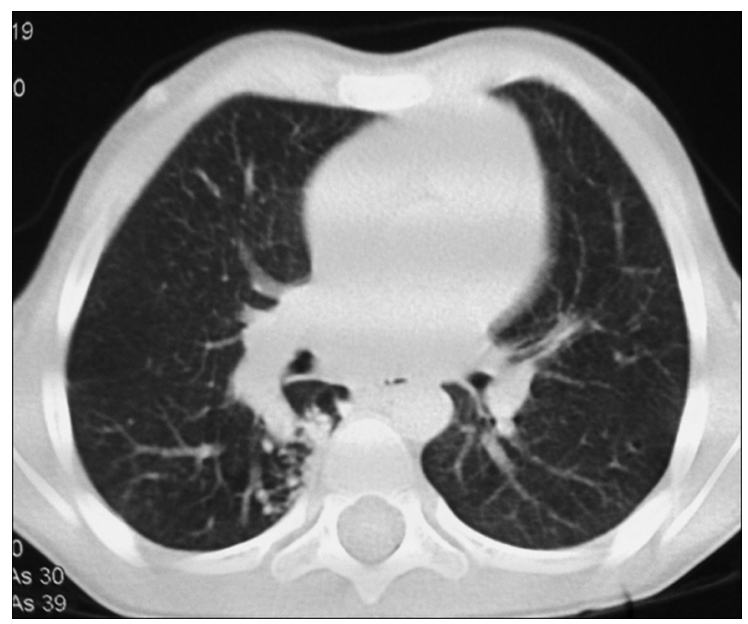

Fig. 3. The right inferior pulmonary vein of third case as a wide tubular structure drains to the azygos vein. There was a big arterial structure branched out from celiac truncus at the lower lobe of the right lung.

at admission: body weight 9,300 g (10-25p), height $75 \mathrm{~cm}(3 \mathrm{p})$, body temperature $36.8^{\circ} \mathrm{C}$, respiratory rate 48 breaths/min, pulse $120 /$ min, blood pressure 90/60 $\mathrm{mmHg}, \mathrm{SpO}_{2}$ $99 \%$. There were no particular findings in system examinations. In the laboratory tests: hemoglobin $10.3 \mathrm{~g} / \mathrm{dl}$, hematocrit $30.7 \%$, WBC $14,200 / \mathrm{mm}^{3}$ (61.4\% polymorphonuclear, $32.2 \%$ lymphocytes), platelets $379,000 / \mathrm{mm}^{3}$, ESR 37 $\mathrm{mm} /$ hour, and C-reactive protein (CRP) 1.31 $\mathrm{mg} / \mathrm{dl}$; biochemical tests were normal. In her chest X-ray, there was unilateral hyperinflation, and as such, a thorax CT was performed. Fissures in the right lung had not completely developed. There was a partial venous anomaly in the inferior pulmonary vein and the right lower lobe of the lung, perfused from the celiac artery (Fig. 3). She was diagnosed with hypogenetic right lung syndrome (venolobar syndrome) based on the current findings. During the angiography, the imaging using nonionic contrast agent administered to the right pulmonary artery revealed reduced blood supply to the lower part of the right lung, and the right inferior pulmonary vein was draining into the azygos vein and continued into the superior vena cava in the phase of pulmonary venous return. The injections into the aortic arch and descending aorta revealed that the pulmonary arteries filled through a conic-shaped patent ductus arteriosus (PDA) and a systemic artery below the diaphragm supplied the lower part of the right lung. The case was discussed at the Thoracic and Cardiovascular Surgery Council, and since her general condition was good, oxygen saturation was around 95-98\% and had no history of recurrent pneumonia, a six-month clinical observation was advised to the patient.

The fourth case was a 2-year-old female admitted to our clinic with digital cyanosis. In her physical examination at admission: body weight 11,200 g (25-50p), height $90 \mathrm{~cm}$ $75 \mathrm{p}$ ), body temperature $36.5^{\circ} \mathrm{C}$, respiratory rate 30 breaths/min, pulse 118 beats/min, blood pressure $80 / 45 \mathrm{mmHg}, \mathrm{SaO}_{2} 75 \%$. Breathing sounds were bilaterally equal and there were no additional sounds. Cardiac auscultation was normal and there were no additional sounds or murmurs. The patient's pulse was taken at an equal rate from the four extremities. There was clubbing deformity of the fingers of the hand and cyanosis of the nails. There were no particular findings in other system examinations. In the laboratory tests: hemoglobin $13.9 \mathrm{~g} / \mathrm{dl}$, hematocrit $39 \%$, WBC $10,800 / \mathrm{mm}^{3}$ (48\% polymorphonuclear, $52 \%$ lymphocytes), platelets $398,000 / \mathrm{mm}^{3}$, ESR $12 \mathrm{~mm} /$ hour and CRP $0.33 \mathrm{mg} / \mathrm{dl}$; biochemical tests were normal. There were polycythemia, cyanosis and clubbing of the fingers, and her echocardiographic examination was normal. Therefore, a thorax CT was performed. Arteriovenous malformations in the right lower lobe, which were connected to the right pulmonary veins and enlarged right pulmonary artery, were revealed. The patient was referred for transcatheter embolization.

The fifth patient was a 13-year-old female, who was admitted to the hospital with a fever and cough. In the physical examination at 
admission: body weight $41 \mathrm{~kg}$ (10p), height $163 \mathrm{~cm}$ (75p), body temperature $36.5^{\circ} \mathrm{C}$, respiratory rate 26 breaths/min, pulse 90 beats/min, blood pressure 110/80 $\mathrm{mmHg}, \mathrm{SpO}_{2}$ $76 \%$. Respiratory system and cardiovascular system examinations were normal. There was no pathological examination finding other than clubbing deformity of the fingers of the hand and cyanosis of lips. In laboratory tests, hemoglobin $17 \mathrm{~g} / \mathrm{dl}$, hematocrit 50\%, WBC $10,130 / \mathrm{mm}^{3}$ (52\% polymorphonuclear, $48 \%$ lymphocytes), platelets $457,000 / \mathrm{mm}^{3}$, and ESR $2 \mathrm{~mm} /$ hour; biochemical tests were normal. The thorax CT showed an arteriovenous malformation characterized by a glomerulus with a diameter of $38 \mathrm{~mm}$, and was nourished by a large pulmonary artery branch in the right medial lobe segment. She was referred for endovascular embolization because of her clinical condition

\section{Discussion}

Pulmonary arteriovenous malformations are generally congenital lesions caused by abnormal capillary development ${ }^{1-4}$. Their etiology is not completely known; on the other hand, some genetic factors are thought to play a role in the formation of disease. Lee et al. ${ }^{3}$ divided bronchopulmonary vascular malformations systematically into seven subcategories (Type A-G) with the "malinosculations theory". Shields et al. ${ }^{4}$, however, created three main categories, as anomalies originating from the pulmonary arteries, pulmonary veins, and lymphatic vessels.

Children account for $10 \%$ of cases, and the incidence increases in the fifth and sixth decades4-10. In 1974, Dines et al. ${ }^{11}$ divided arteriovenous malformations into two groups as those with idiopathic AVMs and RenduOsler-Weber disease (ROWD) (also known as hereditary hemorrhagic telangiectasia: HHT) and those with idiopathic AVMs. The cases with pulmonary AVMs are generally congenital and are observed with ROWD at a rate of $70 \%$. Congenital PAVMs, which are incomplete, and transmitted and inherited by a dominant gene, are more frequently seen in women. PAVMs usually involve the lower lobe, are solitary, and localize superficially. Multiple lesions are seen in $33-50 \%$ of cases and they are often accompanied by HHT ${ }^{12}$. PAVMs accompanied by HHT progress rapidly and their complication rate is quite high 6,12 . While a sole AVM was established in our three diagnosed cases, multiple lesions were found in only one case. Lesions located in the lower lobes were found in two cases, in the middle lobe in one case, and multiple zones were seen in one case.

Congenital pulmonary anomalies can occasionally be seen with vascular malformations. A coexistence of Scimitar syndrome and pulmonary sequestration is called "venolobar syndrome." The components of this syndrome are cardiac anomalies, such as pericardial defects and atrial septal defects in $25 \%$ of the cases, ventricular septal defects, coarctation of the aorta, Fallot tetralogy, pulmonary stenosis, or absence of the inferior vena cava, as well as pulmonary anomalies, such as right lung hypoplasia or partial agenesis, right bronchial system hypoplasia, right pulmonary artery hypoplasia or agenesis, supply of at least one part of right lung from systemic artery, dextroposition of the heart due to right lung hypoplasia, diaphragmatic eventration, phrenic cyst, horseshoe lung, esophageal lung, or gastric lung ${ }^{13}$. Venolobar syndrome was diagnosed in our third patient since an inferior pulmonary venous return anomaly was observed in her thorax CT, there was a sequestration in the right lung lower lobe, right lung hypoplasia, and PDA were detected.

Some of the patients with congenital pulmonary vascular anomaly are asymptomatic. Some patients are diagnosed by typical findings, symptoms, and radiological findings determined in the neonatal and infancy periods. Symptoms can vary in respect to the number and size of pulmonary venous anomalies. While single lesions with a diameter smaller than $2 \mathrm{~cm}$ are generally asymptomatic, cough, shortness of breath, hemoptysis, cyanosis, and epistaxis can be seen in larger lesions. The classical triad (cyanosis, polycythemia, and clubbing of fingers) due to a shunt caused by high flow pulmonary AVM are uncommon in children. Cerebrovascular complications such as paradoxic embolism, hemiplegia, and cerebral abscess can be seen in these patients $6,9,14$. The classical triad was seen in our three patients due to the shunt, caused by high output pulmonary AVM. One of the patients had recurrent lung infections and one had persistent wheezing. 
A chest X-ray is insufficient to diagnose pulmonary vascular anomalies. Pulmonary angiography is the gold standard, yet it is an invasive method. Therefore, pulmonary angiography must be preferred if no diagnosis can be made after all noninvasive analyses or if "coil" embolization is considered in the treatment ${ }^{15}$. The second line imaging method must be thorax CT in the diagnosis of pulmonary vascular anomalies. In the thorax CT, AVMs in particular manifest themselves as serpiginous masses linked to the blood vessels or benign restricted nodular masses. The thorax CT shows the lesion's lobular or segmental localization and its anatomy. In a study carried out by Remy et al. ${ }^{16}$, thorax CT was used in $98.2 \%$ of the patients who were diagnosed with PAVM. All of our patients were diagnosed with thorax CT. Recently three dimensional MRA has been a favored method in the examination of thoracic vascular structures and lesions. It was $100 \%$ successful in the diagnosis of AVM with an artery diameter above $5 \mathrm{~mm}^{16,17}$.

If congenital pulmonary vascular anomalies are not treated, early diagnosis and treatment are of vital importance, since they can cause death as a result of pulmonary and cardiac problems. Patients with pulmonary arteriovenous malformation who have symptoms of hypoxemia, ROWD, and multiple AVM should be treated. Even if the patient is asymptomatic, a treatment must be planned, owing to likely complications if the supplying artery's diameter is larger than $3 \mathrm{~mm}^{5,10,18}$. AVMs were treated in the past with methods such as lobectomy, wedge resection, and arterial ligation prior to transcatheter embolization. Today, transcatheter embolization is successfully used in the treatment of PAVM, leading to hypoxemia and whose supplying artery diameter is larger than $3 \mathrm{~mm}^{6,11,18}$. Surgery, on the other hand, is a curative and safe method in cases that are localized, solitary, and large and do not recover despite embolization or cause hemothorax by rupture ${ }^{5,6,19}$. Because there were hypoxemia findings caused by shunt in our three patients and there were multiple lesions in one patient in whom HHT was thought, and the diameter of AVM was more than $3 \mathrm{~mm}$, they were sent to an appropriate center. The case was diagnosed with venolobar syndrome and discussed at the Thoracic and Cardiovascular Surgery Council. The case was initiated with infective endocarditis prophylaxis, taken under clinical observation, and scheduled for operation according to the control six months later.

In conclusion, vascular malformations of the lung remain silent most of the time and irreversible cardiac and pulmonary problems may have already developed when they are first diagnosed. Therefore, it should be kept in mind that patients can present with complaints other than cyanosis. In rare cases that are refractory to treatment, thorax CT, which is not typically used at the outset for differential diagnosis of wheezing, will allow correct diagnosis.

\section{REFERENCES}

1. Zylak CJ, Eyler WR, Spizamy DL, Stone $\mathrm{CH}$. "Developmental lung anomalies in the adult: radiologicpathologic correlation." Radiographics: a review publication of the Radiological Society of North America, Inc 22 (2002): S25.

2. Gürses D, Ulger Z, Levent E, Ozyürek AR. A very rare case of polysplenia syndrome with congenital diffuse pulmonary arteriovenous fistulas. Turk J Pediatr 2006; 48: 96-99.

3. Lee ML, Lue HC, Chiu IS, et al. A systematic classification of the congenital bronchopulmonary vascular malformations: Dysmorphogeneses of the primitive foregut system and the primitive aortic arch system. Yonsei Med J 2008; 49: 90-102.

4. Shields TW. Congenital vascular lesions of the lungs. In: Shields TW, Cicero JL, Ponn RB, eds. General Thoracic Surgery ( $5^{\text {th }}$ ed). Philadelphia: Lippincot Williams \& Wilkins; 2000: 975-987.

5. Liptay MJ, Ujiki MB, Locicero J. Congenital vascular lesions of the lungs. In: Shields WT (ed). General Thoracic Surgery $\left(6^{\text {th }}\right.$ ed). Philadephia: Lippincot Williams \& Wilkins; 2004: 1144-52.

6. Coley SC, Jackson JE. Pulmonary arteriovenous malformations. Clin Radiol 1998; 53: 396-404.

7. Guttmacher AE, Marchuk DA, White RI Jr. Hereditary hemorrhagic telengiectasia. N Engl J Med 1995; 339: 918-924.

8. Borrero CG, Zajko AB. Pulmonary arteriovenous malformations: clinical features, diagnosis and treatment. J Radiol Nurs 2006; 25: 33-37.

9. Cottin V, Plauchu H, Bayle JY, Barthelet M, Revel D, Cordier JF. Pulmonary arteriovenous malformations in patients with hereditary hemorrhagic telengectasia. Am J Respir Crit Care Med 2004; 169: 994-1000.

10. Gossage JR, Kanj G. Pulmonary arteriovenous malformations. A state of the art review. Am J Respir Crit Care Med 1998; 158: 643-661.

11. Dines DE, Seward JB, Bernatz PE. Pulmonary arteriovenous fistulas. Mayo Clin Proc 1983; 58: 176-181. 
12. Hoffman WS, Wienberg PM, Ring E, Edmunds LH Jr. Massive hemoptysis secondary to pulmonary arteriovenous fistula: Treatment by a catheterization procedure. Chest 1980; 77: 697-700.

13. Woodring JH, Howard TA, Knaga JF. Congenital pulmonary venolobar syndrome revisited. Radiographics 1994; 14: 349-369.

14. Ference BA, Shannon TM, White RI, Zawin M, Burdge CM. Life-threatening pulmonary hemorrhage with pulmonary arteriovenous malformations and hereditary hemorrhagic telangiectasia. Chest 1994; 106: 13871390.

15. White RI Jr. Pulmonary arteriovenous malformations: how do I embolize? Tech Vasc Interv Radiol 2007; 10: 283-290.
16. Remy J, Jardin MR Wattinne L, Deffontaines C. Pulmonary arteriovenous malformations: evaluation with CT of the chest before and after treatment. Radiology 1992; 182: 809-816.

17. Puvanesary M. Three-dimentional gadolinium-enhanced magenetic resonance angiography of pulmonary arteriovenous malformation. Australas Radiol 2002; 46: $189-193$.

18. Vrachliotis TG, Bis KG, Kirsch MJ, Shetty AN. Contrastenhanced MRA in pre-embolization assessment of a pulmonary arteriovenous malformation. J Mag Res Imaging 1997; 7: 434-436.

19. Mann MJ, Kramer MJ, Hall TS, et al. Isolated pulmonary arteriovenous malformations requiring anatomic resection. J Thorac Cardiovasc Surg 2004; 127: 574576. 